\title{
O conhecimento pedagógico do professor de educação fisica da escola pública no Río Grande do Sul - uma etnografia em Porto Alegre
}

Alexandre Scherer*

Vicente Molina Neto**

\begin{abstract}
Resumo
O estudo trata de identificar que conhecimentos sustentam a prática pedagógica do professor de educação física da escola pública da rede estadual de ensino. Nesse sentido, a análise efetiva desta investigação foi centrada nas concepções teóricas, na trajetória profissional e no cotidiano dos professores de educação física.

A metodologia utilizada centrou-se na perspectiva qualitativa de um estudo etnográfico envolvendo dezesseis professores e seis escolas da rede pública estadual de ensino na cidade de Porto Alegre. Este trabalho aponta para a necessidade de compreenderse, com mais profundidade, o cotidiano escolar, através de estudos de perspectiva qualitativa, onde a compreensão das relações que abrangem a comunidade escolar sustente uma ação pedagógica dos professores de educação física, sem desconsiderar o contexto social, político, econômico e cultural.
\end{abstract}

\section{Abstract}

The study examines to identify that knowledge sustain the pedagogic practice of physical education teachers of public school, of the state net of teaching. In that sense, the effective analysis of this study was centered in the theoretical conceptions, in the professional trajectory and in the daily of physical education teachers.

The used methodology was centered in a qualitative perspective of an ethnographic study involving sixteen teachers and six schools of the public state net of teaching in the city of Porto Alegre. This work points for the need of understanding, with more depth the daily school, through studies of qualitative perspective, where the understanding of the relationships that embrace the scholastic community, sustain a pedagogic action of physical education teachers, without disrespecting the social, political, economic and cultural context.

\section{A SOCIEDAde E A Escola PúBliCA}

Transitam no âmbito da escola diferentes concepções sobre o que é educação física e qual a sua finalidade no âmbito da educação escolar. Esta diversidade, além de gerar polêmica na comunidade de investigadores, dificulta a ação pedagógica dos professores na escola, dado o pouco tempo que têm para estudá-las com mais profundidade.

Com o objetivo de compreender melhor os acontecimentos que envolvem a educação física escolar, este estudo procura identificar que conhecimentos são utilizados pelos professores de educação física das escolas públicas da rede estadual de ensino na sua prática cotidiana. Partimos do princípio de que a prática cotidiana do professor de educação física é realizada mediante uma gama de conhecimentos, intuições e concepções que ele vai adquirindo durante sua vida. Como afirma Molina Neto (1996), o que os docentes pensam e crêem está ligado diretamente ao que fazem na escola.

É importante lembrar que esta investigação está impregnada por determinados interesses que emergem de uma visão crítica de mundo, de homem, de sociedade, de educação e de escola. Além disso, levamos em conside- 
ração nossas experiências pessoais como professores da rede pública estadual de ensino e como professores universitários.

Especificamente, sobre a nossa visão de escola, concordamos com o pensamento de Gonçalves (1994) quando diz que:

\begin{abstract}
"A escola é uma instituição social e, como tal, se encontra numa relação dialética com a sociedade em que se insere. Ao mesmo tempo em que reproduz as estruturas de dominação existentes na sociedade, constitui-se em um espaço onde se pode lutar pelas transformações sociais. As práticas sociais trazem a marca da cultura e do sistema dominante, que nelas imprimem as relações sociais que caracterizam a moderna sociedade capitalista..." (p. 32).
\end{abstract}

\section{Particularmente a escola pública é uma instituição fortemente influenciada pela ideologia liberal de educação.}

Sob essa visão, é que são apresentados e selecionados os conhecimentos e saberes que constituem o currículo escolar. Este currículo é fragmentado e objetiva um desempenho positivo nos vestibulares valorizando, assim, a escola particular.

Nesse sentido, notamos que grande parte da população não tem acesso aos bancos universitários e que estes, em geral, vêm de escolas públicas. Segundo Molina Neto (1996) as escolas públicas têm como principais características a gratuidade do ensino, uma maior autonomia pedagógica, uma relação de poder institucional menos evidente, os movimentos sindicais organizados, uma seguridade social e uma liberdade de ação docente.

Para Silva (1992), a escola pública está organizada de forma burocrática e centralizada onde a sua regulamentação prioriza os setores administrativos e não pedagógicos. Isso possibilita que os professores tenham liberdade para determinar suas ações pedagógicas cotidianas.

Particularmente a escola pública é uma instituição fortemente influenciada pela ideologia liberal de educação. Neste sentido, concordamos com o pensamento de Ghiraldelli Jr. (1988) quando diz que:

"... na visão liberal de educação e ensino (compromissada com as classes dominantes), a prática escolar (e também a educação familiar, a educação profisssional, a educação física e desportiva etc.) é entendida como ajustamento do indivíduo à forma de organização social existente. A escola visa educar o aluno para ocupar um lugar na hierarquia social, isto é, no lugar destinado à sua classe social de acordo com suas capacidades e aptidões." (p. 10)

Sob esta visão, Souza $(1988)^{1}$ apresenta dados que reforçam este pensamento como o autoritarismo e a orientação dirigida do professor; a reprodução dos conteúdos, a obediência, a desorganização e a resistência dos alunos. Este quadro também foi observado neste estudo, quando o professor controlava a aula utilizando o esporte como conteúdo prioritário e, quando o aluno apenas seguia suas orientações com algumas resistências como a demora em comparecer aos locais das aulas e a dificuldade de organização para a realização de algumas tarefas determinadas pelo professor.

Além disso, observamos que existe resistência dos professores com relação a mudanças no cotidiano da escola pública, tanto nas questões pedagógicas como em relação à parte administrativa. Nesse sentido, por exemplo, os professores seguem um procedimento básico de aula voltado ao esporte recreativo, não valorizam o planejamento e se tiverem que unir turmas ou ceder o seu espaço de aula para outras atividades eles o fazem sem muita resistência.

\section{A Aula de EDUCAÇÃo FísICA}

Já é público, na nossa área de conhecimento, que os professores de educação física que atuam nas escolas tiveram uma formação inicial generalista (Betti e colaboradores, 1988) durante as décadas de 70 e 80 (Daolio, 1995) onde o modelo de esporte de alto rendimento foi o principal conteúdo das aulas de educação física escolar. A finalidade dessas ações era, portanto, a de formar uma elite esportiva nacional, e disseminou-se publicamente a idéia de que da escola sairiam os atletas do futuro. Os professores formados nesta época tiveram a influência das legislações do Ministério da Educação ${ }^{2}$ e do movimento "Esporte para Todos" além de trazer, em geral, uma cultura esportiva 
anterior ao período da graduação que, em muitos casos, os fez escolherem sua profissão.

Com este pensamento, acreditávamos encontrar, através da observação das aulas de educação física da escola pública em Porto Alegre, aulas tradicionais voltadas para o desenvolvimento de gestos técnicos esportivos como citam Souza (1988) e Molina Neto (1993).

Mas a investigação que nos levou ao campo para observar os professores de educação física e suas aulas mostraram outros fatos, como veremos adiante.

\section{DEFINIÇÃO DO PROBLEMA}

Partindo destas concepções iniciais, construímos o problema de pesquisa que se materializou em responder a seguinte questão:

Quais os conhecimentos pedagógicos que sustentam a prática docente do professor de educação física e que relações podem ser feitas entre o conhecimento identificado e a sua aula na escola pública da rede estadual de ensino, de $5^{\mathrm{a}}$ a $8^{\mathrm{a}}$ sériesXXXXX

\section{O CONHECIMENTO PEDAGÓGICO DO}

PROFESSOR DE EDUCAÇÃO FÍSICA

Os autores consultados sobre a temática consideram, em geral, que o professor tem um conhecimento ou saber que envolve mais do que a sua formação inicial e permanente para realizar suas atividades cotidianas. Tardif e colaboradores (1991) consideram este como saber docente. Cunha (1992) chama de conhecimento do professor. Pimenta (1999) denomina de saberes pedagógicos enquanto que Woods (1995) e Molina Neto (1996) chamam-no de conhecimento pedagógico.

Nesse sentido, nosso objetivo, neste trabalho, foi o de identificar os conhecimentos de que o professor de educação física das escolas públicas da rede estadual de ensino, em Porto
Alegre, lança mão para sustentar a sua prática docente no cotidiano das aulas.

Assim, consideramos uma visão de conhecimento que estabelece relações com o mundo vivido e torna-se, então, um conhecimento com características individuais, que vai se construindo na trajetória docente do professor e, por isso, muitas vezes, é diferenciado, influencia e é influenciado pelo meio no qual atua.

Desta forma, consideramos o conhecimento pedagógico como as representações que o professor de educação física têm sobre a sua prática, envolvendo conteúdos, métodos didáticos e estrutura da sua aula; sobre sua formação como profissional, tanto inicial como permanente; sobre sua realidade social, política, econômica e cultural; sobre as suas concepções de educação, escola e educação física; e sobre a sua experiência docente.

\section{DeCisõEs MetodolóGiCAS}

Para responder ao problema de investigação, optamos pela perspectiva qualitativa de caráter etnográfico, já que este estudo procura interpretar as falas e as ações dos sujeitos do estudo procurando desvelar seus significados.

Foram selecionadas seis escolas de diferentes regiões da cidade de Porto Alegre e dezesseis professores que participaram do estudo.

Inicialmente realizamos um estudo preliminar que, segundo Negrine (1999), é um passo importante para a validação de dados na pesquisa qualitativa. Tal procedimento metodológico concretizou-se através de uma observação aberta de cada aula dos professores. Estas primeiras observações serviram de sustentação para criar uma observação semi-estruturada onde aspectos como o conteúdo da aula, a metodologia do professor, as relações que o professor estabelece no ambiente da escola, as características das turmas, seu espaço
Quais os conhecimentos pedagógicos que sustentam a prática docente do professor de educação física e que relações podem ser feitas entre $o$ conhecimento identificado e a sua aula na escola pública da rede estadual de ensino, de $5^{a}$ a $8^{a}$ séries? 
físico e seu material de trabalho foram analisados.

Através da análise das observações foi estabelecido o roteiro da entrevista semiestruturada que inicialmente foi realizada com dois sujeitos não participantes do estudo. Este procedimento serviu para qualificar o instrumento em relação a validade das informações conseguidas. Em seguida a entrevista foi realizada com os demais professores participantes do estudo.

Os questionamentos feitos aos professores foram os seguintes:

1) Para você, para que serve a escola?

2) Existem fatores externos à escola que influenciam as suas atividades como professor na escola?

3) Na sua opinião, por que a educação física faz parte do currículo escolar?

4) Como é o planejamento das suas atividades?

5) De onde você acredita que vieram os conhecimentos que utiliza na sua aula?

6) De tudo o que você aprendeu, o que é utilizado significativamente na sua prática?

7) Descreva como é a sua aula de educação física?

8) A sua atividade sofre influência de outros setores da escola?

As interpretações foram realizadas através da técnica de triangulação dos dados que, segundo Croll (1995), é um método de reunião de dados através de vários instrumentos de coleta onde o investigador procura informações sobre as mesmas características dos indivíduos. Procura-se compreender um fenômeno através de mais de uma perspectiva.

Sob esta visão, a triangulação de dados foi realizada entre as informações do referencial bibliográfico que versava sobre a escola pública, a educação física escolar e o conhecimento pedagógico do professor, a interpretação das observações das aulas de educação física e a interpretação das falas dos professores de educação física nas entrevistas.

A análise das entrevistas revelou inicialmente um total de 336 unidades de significado que se transformaram em 18 categorias de análise que foram trabalhadas em três grandes blocos temáticos nos quais vamos concentrar nossa atenção até o final deste artigo.

\section{CONCEPÇÕES TEÓRICAS QUE COMPÕEM O CONHECIMENTO PEDAGÓGICO DO PROFESSOR DE EDUCAÇÃo FÍSICA}

Os professores participantes do estudo admitem existir uma interação entre a escola e a sociedade, porém, de forma muito restrita. Esta visão está relacionada com a domesticação dos alunos às regras sociais e com a formação para o trabalho, o que reflete indicativos da presença do pensamento liberal que permeia majoritariamente a sociedade atual. Os poucos professores que traduzem uma visão crítica e de modificação do "status quo " social não refletem isso em sua prática cotidiana. Parece, ainda, haver um distanciamento entre a educação física e as outras atividades escolares, pois não interagem como um todo, fato que restringe sua participação no processo de transformação social. Neste sentido, a falta de sustentação teórica para a prática aparece como evidência nas atitudes e nas falas dos professores de educação física participantes deste estudo.

Abordando as concepções sobre a educação física mais evidenciadas pelos sujeitos do estudo, notamos, em suas falas e ações, três visões que aparecem já em outros estudos como o de Bracht e colaboradores (1999) com professores da rede pública estadual no Estado do Espírito Santo $^{4}$ que são: a socialização do aluno, a formação global da criança e a promoção da saúde. Nilton ${ }^{5}$, um dos sujeitos do estudo diz:

\footnotetext{
"Bom, eu acho que... é a ... a matéria, em termos sociais, mais importante da escola... porque trás o convívio do aluno cornos colegas... com os professores, aonde é uma atividade mais aberta, mais livre... que eles conseguem colo-
} 
car para fora, toda a ... a sociabilidade que eles tem, e que não acontece em outras atividades, como historia, física, química... matemática, né?..."

Neste sentido, quando os professores relatam a socialização do aluno como uma das principais justificativas da educação física, eles não apresentam, de forma organizada, como vêem a sociedade atual e como vislumbram um modelo ideal. Por isso, a representação política e social aparece de forma superficial na fala dos participantes do estudo. Parece faltar ao professor de educação física da escola pública uma visão mais aprofundada da sociedade, das relações de poder e das formas possíveis de transformação social que podem ser desenvolvidas pela escola. Percebemos, também, que as concepções dos professores sobre a socialização dos alunos estão relacionadas, no seu cotidiano, com as atividades de avaliação, com a valorização da presença e da participação efetiva dos alunos nas aulas de educação física.

Já sobre a formação global do aluno, notamos que os professores demonstram muitas dificuldades em estruturar uma idéia sobre este assunto. Em geral, o professor aborda este tema de forma muito superficial. As principais características apresentadas neste sentido voltaram-se a atividades diferenciadas que a educação física promove na escola, como o desenvolvimento corporal através das atividades físicas, a diferença de relação existente entre os alunos e os professores de educação física e a própria socialização através dos jogos esportivos coletivos. Segundo Bento:

"Eu justificaria a educação física, porque... ela faz parte do desenvolvimento integral do ser humano, né? Então, ela não poderia ficar de fora do currículo escolar."

Já, sobre a perspectiva de manutenção ou promoção da saúde dos alunos, através das aulas de educação física na escola, o que mais chamou a atenção foram as afirmações dos participantes do estudo voltadas para a adaptação do corpo às pressões sociais (adaptação dos alunos à sociedade atual) ou às pressões vindas do mercado de trabalho (formação para o traba-

1ho). Estas duas visões sugerem que os professores de educação física da escola pública são muito influenciados pela pedagogia liberal que, publicamente, propõe a melhoria da saúde da população, mas que estrategicamente objetiva, em primeiro lugar, o rendimento do trabalhador. Neste sentido, Márcio diz que:

"Saúde, né? Bem estar, a saúde, a qualidade de
vida... hã... então, não ficar obeso, né? E saber
que a atividade física ela é boa para o organismo,
né? Não só a parte lúdica, o lazer, o brincar, mas
também para ... para permanecer saudável, né?
Para evitar doenças."

Como podem, então, os professores de educação física contribuir com as transformações sociais através de suas atividades cotidianas na escola, se eles demonstram dificuldades em visualizar uma sociedade diferenciada, uma formação dos alunos da escola em prol de uma modificação do status quol É possível pensar, então, que as visões liberais de educação, escola e sociedade fazem parte do conhecimento pedagógico do professor de educação física.

\section{A TrajetóRIa do Professor de EdUCAÇão FíSICA: A FORMAÇÃO E A EXPERIÊNCIA}

Neste processo todo, os professores identificam quatro fatores que caracterizam a origem do seu conhecimento: a vida esportiva anterior à formação inicial; a formação inicial; a formação permanente; e a sua experiência docente.

Sobre a formação inicial, Molina Neto (1996) diz que as principais áreas desenvolvidas nos cursos de graduação eram as áreas biológica, psicológica, pedagógica e de técnicas corporais, e estas disciplinas faziam o acadêmico ter um pensamento linear e técnico.

Os professores participantes do estudo não apresentaram novidades com relação às informações de seus cursos de graduação. A característica mais evidente que observamos na fala dos professores, e que se reflete em sua prática cotidiana, é a relação existente entre a formação inicial e o esporte institucionalizado.

\section{Como podem, então, os professores de educação física contribuir com as transformações sociais através de suas atividades cotidianas na escola, se eles demonstram dificuldades em visualizar uma sociedade diferencia- da, uma formação dos alunos da escola em prol de uma modificação do status quo?}




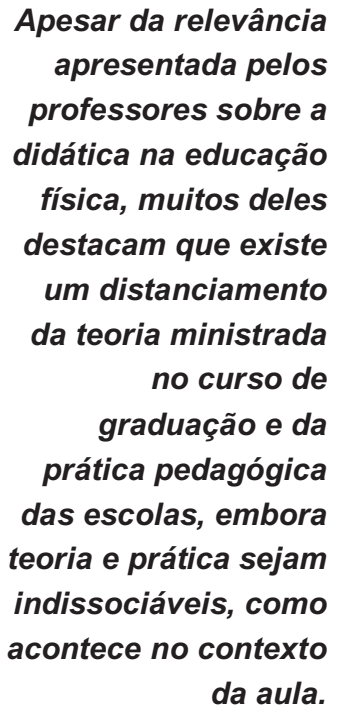

da aula.

Esta tendência esportiva verificada na fala dos professores é confirmada por Borges (1998) quando afirma que a formação inicial se utiliza dos esportes para desenvolver o paradigma da performance esportiva, no qual a aprendizagem mecânica e descontextualizada dos fundamentos técnicos é evidenciada na formação do professor. Neste sentido Osvaldo diz que:

\begin{abstract}
"Eu acho que parte dos conhecimentos da faculdade, também, né? De coisas ... das minhas vivências dentro da ... dentro da faculdade, das minhas vivências na escola ... na minha escola, na faculdade ... no mundo esportivo que eu joguei tudo quanto foi esporte, (incompreensível) Eu pratiquei tênis, basquete, handebol, futebol, vôlei, natação, atletismo ..."
\end{abstract}

Apesar da relevância apresentada pelos professores sobre a didática na educação física, muitos deles destacam que existe um distanciamento da teoria ministrada no curso de graduação e da prática pedagógica das escolas, embora teoria e prática sejam indissociáveis, como acontece no contexto da aula.

Então, é relevante lembrar que o contexto em que se formou a maioria dos professores pesquisados é o de uma época onde a concepção esportiva da educação física se fez bastante presente.

Desta forma, através da valorização de habilidades técnicas e de gerenciamento de ensino, os professores desenvolveram um caminho voltado ao esporte e ao rendimento.

Já, em relação à formação permanente do professor de educação física, foi possível identificá-la como um grupo de atividades específicas que acontecem após o término do curso de graduação.

Dois autores possibilitam uma compreensão mais aprofundada sobre a formação permanente do professor. Imbernón (1997) conceitua formação permanente como uma atualização científica, psicopedagógica e cultural, complementar e aprofundada a partir da formação inicial, com a finalidade de aperfeiçoar sua atividade profissional.
Para Molina Neto (1996), a formação permanente está ligada à atualização, ao controle do trabalho, ao salário, à promoção da carreira, à conformidade, à exploração e à colonização. $\mathrm{O}$ autor considera como tipos de formação permanente os cursos de pós-graduação, congressos, seminários, encontros e pequenos cursos com um mínimo de horas previstas.

Neste sentido, os professores citam, principalmente, os cursos de pós-graduação e os outros cursos menores realizados em eventos como congressos, encontros, seminários, etc. Os cursos denominados de "pós-graduação" são caracterizados por uma abordagem específica, com duração de, no mínimo, um ano, estando ligados a uma instituição de ensino superior.

Em geral, os professores, ao final do curso de graduação, entram no mercado de trabalho ou vêem a perspectiva de entrar nele. Seus interesses na formação permanente estão diretamente voltados, com algumas exceções, ao seu campo de trabalho.

Parece que a justificativa de realizar um curso de pós-graduação está na possibilidade de uma melhor qualificação, de atualização, de aplicação prática e de progresso na carreira do magistério público estadual. Para Márcio:

"... depois, com o passar dos anos, a gente que
tem que se atualizar, né? Então, hã... principal-
mente a educação física ela é... está sempre se
modificando como todas as áreas, né? Se a gente
não se atualiza a gente fica meio que por fora e...
então, eu sempre procurei me atualizar, na parte
de atividade, atividade física..."

Outros cursos, de menor porte, são identificados pelos professores como fazendo parte de sua formação permanente. São cursos caracterizados por terem uma curta duração, serem altamente específicos e técnicos. Os professores os realizam mediante os interesses particularmente ligados ao seu momento profissional. Eles acreditam que os cursos de pequena duração configuram o meio mais adequado de se atualizarem em relação a conteúdos e procedimentos de ensino. Realizam, quando possível, os cursos mais voltados à sua própria área 
e que podem trazer uma resposta mais imediata aos seus problemas cotidianos que, na maioria dos casos, estão relacionados ao esporte escolar. O período, logo após o término do curso de graduação, parece ser o mais relevante em busca de novos conhecimentos para o professor, tanto para se afirmar na profissão, como para buscar um lugar no mercado de trabalho.

É importante ressaltar que os professores vão se acomodando à medida que seus anos de magistério vão passando. Neste sentido, Silva (1995) apresenta os fatores determinantes da identidade do professor de ensino fundamental: a desvalorização pelo baixo salário; o acúmulo de funções o que acarreta falta de tempo para outras funções necessárias; a dificuldade de formação ou atualização causando uma desorientação; o isolamento pela utilização de uma burocracia escolar; a dependência de especialistas; a falta de condições no ambiente profissional; e a influência ideológica que causa uma introversão, uma alienação política e um idealismo romântico. Neste sentido, os professores vão, com o passar do tempo, sustentando cada vez mais sua prática pedagógica em sua experiência.

Com isso, a experiência docente traduziu-se como a principal fonte de conhecimento para a prática cotidiana do professor de educação física. Então, durante a sua trajetória profissional, o professor modifica suas estratégias de ação sustentadas, principalmente, na sua experiência profissional. As atitudes mais autoritárias e voltadas ao desenvolvimento da técnica esportiva, desenvolvidas no início da carreira, são trocadas, em geral, por diálogos e atividades mais recreativas e lúdicas normalmente através da utilização do esporte coletivo institucionalizado que representou a metodologia predominante no campo de estudo.

\section{O COTIDIANO DO PROFESSOR DE EDUCAÇÃO FísICA}

Analisando as decisões metodológicas que tomamos e o que aprendemos no processo de construção desta investigação, podemos dizer que este estudo do tipo etnográfico possibi-

litou uma inserção de forma aprofundada nas escolas investigadas. Esta convivência com a cultura escolar ampliou algumas visões que esclareceram como vivem e como pensam os professores de educação física da rede pública estadual de ensino. Em geral, os professores são profissionais que não estão contentes com a sua situação funcional e financeira no magistério público estadual. Muitos deles desenvolvem outras atividades, não somente voltadas para a educação, mas, em muitos casos, deixando a atividade do magistério em segundo plano, sem tempo nem recursos financeiros para se atualizarem.

Nesta perspectiva, identificamos que o esporte desenvolvido de forma recreativa é o modelo dominante nas aulas de educação física observadas. Ao contrário do que apontavam a bibliografia consultada e a nossa própria experiência, o desenvolvimento de uma metodologia em busca de um rendimento técnico e físico foi muito pouco observado neste estudo. Como exemplo, temos a descrição da aula de Giovana. Para ela:

"... Então com os... 1." grau eu faço a chamada,
converso com eles, sobre o que que a gente vai
fazer hoje, o que vamos trabalhar, vamos correr,
vamos caminhar, vamos fazer uma ginástica... ou
vamos partir direto para o desporto assim para
jogar, né?"

Apesar disso, não descartamos, porém, que a estrutura do modelo de esporte de alto rendimento está enraizada na cultura do professor de educação física fazendo parte, assim, do seu conhecimento pedagógico. Notamos que este fato aconteceu quando os professores referiram-se aos locais de aula e aos materiais utilizados valorizando os que mais se aproximavam do esporte institucionalizado. Neste sentido, Paula diz que:

\footnotetext{
"... o espaço que nós temos, é razoável, só que quando chove fica difícil de trabalhar porque, o pátio é descoberto e a gente tem uma área hã... que tem, que é o pátio que é descoberto, e tem debaixo dos pilares, tem debaixo da escola, que a gente também consegue usar, apesar de ser baixo, mas dá para quebrar o galho. E nós temos um salão, onde... a gente pode trabalhar bem, ele não tem um espaço assim, a medida oficial, mas a gente consegue trabalhar."
}

\section{Com isso, a experiência docente traduziu-se como a principal fonte de conhecimento para a prática cotidiana do professor de educação física.}


Neste sentido, por mais que propostas progressistas de educação venham a ser desenvolvidas para a escola pública, sem uma valorização financeira do professor, elas vão esbarrar no imobilismo e na apatia dele e da sua categoria como um todo, inviabilizando sua aplicação.
Mesmo que a perspectiva recreativa seja a mais observada durante as aulas de educação física, as regras oficiais, como o número exato de jogadores, a necessidade de ter um árbitro e as novas regras vinculadas ao voleibol, entre outras, caracterizaram que o modelo de esporte de alto rendimento ainda serve como sustentação da prática pedagógica dos professores de educação física da escola pública. Ainda, nas nossas observações, identificamos a exclusão de alunos do jogo esportivo, apesar de esforços dos professores em fazer todos participarem.

Apareceram também outras formas de trabalho como aulas de ginástica, de formação corporal e de aprendizado técnico. Neste sentido, é relevante salientar que o professor de educação física da escola pública tem uma autonomia pedagógica quase que total. Em geral, os participantes do estudo sustentam as suas aulas na sua experiência profissional e na análise de seu local e material de aula. Por isso, normalmente, os professores de educação física não planejam suas atividades, considerando que elas estão interiorizadas em sua mente. $\mathrm{O}$ compromisso com a apresentação de um plano de curso é, para eles, um simples trâmite administrativo, que, na maioria das vezes, é apresentado de forma descontextualizada da prática cotidiana e repetido de um ano para outro. Encontramos planos de ensino antigos e copiados de outros e, em uma das escolas não existia o planejamento da educação física.

Neste mesmo sentido, as orientações da Secretaria de Educação e do Ministério da Educação, que regulamentam as práticas cotidianas na escola, não são consideradas por eles e muitos nem chegam a conhecê-las, como é o caso dos recentes $\mathrm{PCNs}^{6}$. Esta desinformação está diretamente ligada à desvalorização do magistério público da rede estadual de ensino. Neste sentido, por mais que propostas progressistas de educação venham a ser desenvolvidas para a escola pública, sem uma valorização financeira do professor, elas vão esbarrar no imobilismo e na apatia dele e da sua categoria como um todo, inviabilizando sua aplicação.

Sob esta perspectiva, a autonomia dos professores de educação física somente sofre influências da parte administrativa da escola quando esta se apropria do seu espaço de aula para outras atividades, ou quando sugere um acúmulo de turmas nas suas aulas por falta de professores de outras disciplinas o que foi observado em diversas oportunidades.

Finalizando esta seção, é importante sinalizar a influência da mídia, principalmente da televisão, que tem uma parcela muito grande na divulgação do modelo de esporte de alto rendimento na sociedade em geral. Neste sentido, Bento diz que:

"... Meios de comunicação, é ... eu procuro muitas vezes executar alguma atividade na minha aula relacionada com o que está acontecendo, por exemplo, tá acontecendo o campeonato gaúcho (...) e se faz uma competição, dentro da aula. Se está sendo realizado o campeonato brasileiro, idem. Se está sendo realizado a copa Mercosul ou libertadores da América, sempre pegando aquelas equipes, né? Com suas respectivas cidades e países... para realizar uma competição na sala de aula."

A valorização dos espaços publicitários ligados ao esporte influencia, de maneira muito particular, a vida de alunos e professores, que se espelham neste modelo para desenvolver suas atividades físicas cotidianas o que se constitui, então, em mais uma referência do conhecimento pedagógico do professor de educação física.

\section{CONSIDERAÇÕES FINAIS}

As inquietações subjacentes a este estudo estiveram direcionadas no sentido de entender como os professores de educação física constróem, organizam e sistematizam a aula que ministram na escola pública da rede estadual de ensino, de $5^{\mathrm{a}}$ a $8^{\mathrm{a}}$ séries. Ao buscar esclarecimentos sobre quais os conhecimentos utilizados pelos professores de educação física e como servem de sustentação para a prática cotidiana da aula acreditamos que a trajetória profissional realizada pelos professores, as influências externas vindas das políticas públicas e da mídia eletrônica, bem como as influências internas, principalmente as relativas à administração escolar e às relações çom os seus alunos, fazem parte de um contexto que formam o conhecimento pedagógico destes professores. 
Não foi possível perceber nas escolas da rede pública estadual de ensino, participantes do estudo, ações de resistência ao modelo social vigente que certamente existem, mas não com clareza suficiente para identificar sua natureza. Ao contrário, as ações identificadas refletem, em muito, a estrutura da sociedade capitalista através dos conteúdos, objetivos, metodologias e avaliações utilizadas.

Gostaríamos de ressaltar que não é objetivo deste estudo generalizar suas interpretações. Acreditamos que muitas situações visualizadas nesta investigação acontecem em outros meios escolares, mas somente podem ser comparadas e utilizadas como referência a partir da compreensão do contexto de cada universo pesquisado.

Consideramos, então, que o conhecimento pedagógico do professor de educação física tem sua origem na formação pessoal e profissional que, para um melhor entendimento, divido em dois grupos:

a) As experiências de vida e esportivas, a formação inicial e a formação permanente.

Através destas atividades, o professor de educação física sustenta uma visão de sociedade, de educação, de escola e de educação física. Normalmente, este pensamento que se caracteriza por uma perspectiva tradicional e vislumbra o conteúdo esportivo como seu principal modelo, refletindo seus aspectos competitivos e de rendimento pregados pela ideologia dominante;

\section{b) A experiência docente.}

De acordo com este estudo, a experiência do professor de educação física é o fator orientador principal da prática pedagógica utilizada pelos participantes do estudo. Através dela os professores de educação física determinam a metodologia a ser aplicada na aula, refletindo sobre o seu espaço físico, as características das turmas e dos alunos e o material utilizado nas suas atividades. Conforme a sua experiência, o professor de educação física descobre a sua autonomia na escola pública e descarta, em geral, as orientações administrativas e pedagógicas vindas da Secretaria de Educação e do Ministério da Educação, aceitando, porém, a influência da mídia eletrônica que reforça os conteúdos esportivos voltados ao modelo de alto rendimento.

Constatamos, neste momento, a dificuldade de ver, após este estudo, a educação, a escola e a educação física afastada de um contexto social que valoriza o consumo e que prega o distanciamento entre as classes sociais. Nosso questionamento faz-se no sentido de organizar e executar, na prática cotidiana da escola pública, uma metodologia que propicie à comunidade escolar uma forma de refletir e agir que busque uma autonomia dos alunos numa visão mais humana da sociedade. Então, podemos afirmar que existe a necessidade de um maior envolvimento e comprometimento dos professores de educação física com as questões sociais.

Este trabalho aponta para a necessidade de compreender-se, com mais profundidade, o cotidiano escolar, através de estudos de perspectiva qualitativa, onde o entendimento das relações que abrangem a comunidade escolar sustente uma ação pedagógica dos professores de educação física, sem desconsiderar o contexto social, político, econômico e cultural, engajando-os num movimento crítico em busca de uma sociedade mais igualitária e humana.

Auxiliar os professores de educação física para apurar uma visão mais crítica da sociedade $\mathrm{e}$ para que estejam mais envolvidos nos processos políticos e sociais é o que acreditamos ser a possível contribuição deste trabalho. Isto só poderá ocorrer na medida em que os professores tenham oportunidade e formação para sistematizar o conhecimento que desenvolvem na experiência cotidiana.

\section{REFERÊNCIAS BIBLIOGRÁFICAS}

BETTI, Mauro; OLIVEIRA, José G. M.; OLIVEIRA, Wilson M. Educação Física e o Ensino de $1^{\circ}$ grau: Uma Abordagem Crítica. São Paulo: EOU, 1988. $71 \mathrm{p}$.

BORGES, Cecília Maria Ferreira. O Professor de Educação Física e a Construção do Saber. Campinas: Papirus, 1998. 176 p.

BRACHT, Valter; DIAS, Andreia; SANTOS, Emilene C. dos; PAIVA, Fernanda; CAPARROZ, Francisco E.; POLATI, Giulliana V; FRADE,

\section{Acreditamos que muitas situações visualizadas nesta investigação acontecem em outros meios escolares, mas somente podem ser comparadas e utilizadas como referência a partir da compreensão do contexto de cada universo pesquisado.}


José C; SOUZA, Nilza A. S.; AROEIRA, Kalline R; SCHNEIDER, Ornar; PIRES, Rosely MS.; DELLA FONTE, Sandra S. Diagnóstico da Educação Física Escolar do Espírito Santo: O Imaginário Social do Professor. IN: CONGRESSO BRASILEIRO DE CIÊNCIAS DO ESPORTE, 11, 1999, Florianópolis. Anais... Florianópolis: UFSM, 1999. p. 183-192.

CROLL, Paul. La Observación Sistemática en ei Aula. Madrid: Muralla, 1995. 222 p.

CUNHA, Maria Isabel da. O Bom Professor e sua Prática. 2. ed. Campinas: Papirus, 1992. 182 p.

DAOLIO, Jocimar. Da Cultura do Corpo. Campinas: Papirus, 1995. 105 p.

GHIRALDELLI JÚNIOR, Paulo. Educação Física Progressista: a pedagogia crítico-social dos conteúdos e a Educação Física brasileira. São Paulo: Loyola, 1998. 63 p.

GONÇALVES, Maria Augusta Salin. Sentir, Pensar e Agir: Corporeidade e Educação. Campinas: Papirus, 1994. 197 p.

IMBERNÓN, Francisco. La Formación dei Profesorado. Barcelona: Paidós, 1997. 161 p.

MOLINA NETO, Vicente. A Prática do Esporte nas Escolas de $1^{\circ}$ e $2^{\circ}$ Graus. Porto Alegre: Ed. Universidade Federal do Rio Grande do Sul, 1993. 79 p.

MOLINA NETO, Vicente. La Cultura Docente del Professorado de Educación Física de las Escuelas Públicas de Porto Alegre. Barcelona: Universitat de Barcelona, 1996. 475 p. (Tese, Doutorado em Filosofia e Ciências da Educação).

NEGRINE, Aírton. Instrumento de Coleta de Informações na Pesquisa Qualitativa. In: MOLINA NETO, Vicente; TRIVINOS, Augusto N. S. A Pesquisa Qualitativa em Educação Física: alternativas metodológicas. Porto Alegre: Editora da UFRGS/ Sulina, 1999. p. 61-93.

PIMENTA, Selma Garrido. Formação de Professores: Identidade e Saberes da Docência. In: PIMENTA, Selma Garrido (org.). Saberes pedagógicos e atividade docente. São Paulo: Cortez, 1999. p. 15-34.

RIO GRANDE DO SUL. Conselho Estadual de Educação. Coletânea de Leis de Ensino. 2. ed. Porto Alegre: 1981, 159 p.

SILVA, Ezequiel Theodoro da. Professor de $1^{\circ}$ Grau: Identidade em Jogo. Campinas: Papirus, 1995. $130 \mathrm{p}$.

SILVA, Tomaz Tadeu da. O que Produz e o que Reproduz em Educação. Porto Alegre: Artes Médicas, 1992. 188 p.
SOUZA, Jorge Luiz de. A Educação Física de 5" à 8 Séries: Uma análise crítica da prática em escolas de Porto Alegre. Porto Alegre: UFRGS, 1988. 137 p. (Dissertação, Mestrado em Educação).

TARDIF, Maurice; LESSARD, Claude; LAHAYE, Louise. Os Professores Face ao Saber: esboço de uma problemática do saber docente. Teoria e Educação, Porto Alegre, v. 4. p. 215-233, 1991.

WOODS, Peter. La Escuela Por Dentro: La etnografía en la investigación educativa. 3. ed. Barcelona: Paidós/MEC, 1995. p. 213.

\section{NoTAS}

${ }^{1}$ Souza fez um estudo comparativo entre a educa ção física de uma escola particular e uma escola pública de Porto Alegre.

${ }^{2}$ Como exemplos podemos citar o Decreto número 69.450 que estabeleceu as normas de funcionamento da educação física nas escolas de $\mathrm{I}^{\circ}$ e $2^{\circ}$ graus, e a Lei de número 6.251 onde o Ministério da Educa ção cria o Plano Nacional de Educação Física e Desportos (PNED).

${ }^{3}$ Acreditamos na divulgação do modelo de esporte de alto rendimento através do movimento EPT, no entanto, verificamos, também, que este movimento proporcionou o acesso de classes populares aos es portes, nem sempre sob uma visão competitiva.

${ }^{4}$ Este estudo é centrado no trabalho pedagógico do professor de educação física e aborda o planejamen to, a preparação das aulas, a escolha dos materiais, a avaliação da aula, a avaliação dos alunos e a sua própria avaliação, bem como os conteúdos a serem ministrados e a metodologia adotada.

${ }^{5}$ Todos os nomes dos professores citados neste es tudo são fictícios.

${ }^{6}$ Planos Curriculares Nacionais.

\section{UNITERMOS}

Educação física escolar; conhecimento pedagógico; formação de professores; educação física.

*Alexandre Scherer é Mestre em Ciências do Movimento Humano pela ESEF/UFRGS e Professor do Curso de Educação Física do Instituto Porto Alegre (IPA).

**Vicente Molina Neto é Doutor pelo Departamento de Didática e Organização Educativa da Universidade de Barcelona-ES. Professor de Graduação e Pós-Graduação de ESEF/UFRGS. 